\title{
PRIMEIROS REGISTROS DE BRACHYURA PARA O LITORAL DE SANTA CATARINA, BRASIL: (DECAPODA: DROMIIDAE, XANTHIDAE E INACHOIDIDAE).
}

\author{
IRECE F. MACHADO ${ }^{1,2}$; RONY R. R. VIEIRA ${ }^{1} ;$ \& FERNANDO D'INCAO ${ }^{1}$ \\ ${ }^{1}$ Universidade Federal do Rio Grande - Instituto de Oceanografia - Laboratorio de Crustaceos Decápodes - Programa de Pós-Graduação em \\ Oceanografia Biológica, Caixa Postal 474, 96201-900 - Rio Grande - RS - Brazil. ${ }^{2}$ irecemachado@furg.br
}

\begin{abstract}
New brachyuran crabs records from Santa Catarina coast, Brazil (Decapoda: Dromiidae, Xanthidae and Inachoididae). Three species were collected, Hypoconcha arcuata, Speocarcinus carolinensis and Pyromaia tuberculata. These records represent a distribution extension for $H$. arcuata previously cited to São Paulo coast and $P$. tuberculata to Paraná coast. S. carolinensis had previous records from São Paulo and Rio Grande do Sul coasts and now complete the distribution for Santa Catarina state.
\end{abstract}

\section{INTRODUÇÃO}

Os braquiúras se distribuem em todos os oceanos, desde a praia até as grandes profundidades. Existem cerca de 6.793 espécies, sendo que 350 delas ocorrem na costa brasileira $(\mathrm{Ng}$ et al. 2008).

A familia Dromiidae é representada por Hypoconcha arcuata Stimpson, 1858, tendo o estado de São Paulo como limite austral, já Pyromaia tuberculata (Lockington, 1876) (Inachoididae) tem sua distribuição limite no estado do Paraná. A distribuição geográfica de Speocarcinus carolinensis Stimpson, 1859 (Xanthidae), mostra muitas disjunções, provavelmente, devidas à falta de coleta, sendo citada apenas para os estados do Amapá, São Paulo e Rio Grande do Sul (Melo 1996). Este trabalho tem por objetivo contribuir ao conhecimento da distribuição dessas espécies presentes na costa do Estado de Santa Catarina, Brasil.

\section{MATERIAL E MÉTODOS}

Os exemplares foram capturados na enseada

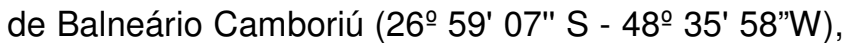
que é uma área tradicional de pesca artesanal no litoral de Santa Catarina. As coletas mensais foram realizadas durante 0 período de maio/2008 a abril/2009, através de arrastos de 15 minutos, utilizando um barco característico da frota artesanal camaroeira (barco tangoneiro - double-rig), redes com malhas de $3,0 \mathrm{~cm}$ no corpo e $2,0 \mathrm{~cm}$ no saco e os arrastos realizados a uma velocidade média de 2,0 nós.

Os exemplares de $H$. arcuata e $P$. tuberculata foram coletados em agosto/08, enquanto $S$. carolinensis foram coletados em novembro/08.

O material coletado (Tabela1) está depositado na coleção científica do Laboratório de Crustáceos Decápodes no Instituto de Oceanografia da Universidade Federal do Rio Grande, Rio Grande do Sul.

Tabela 1. Larguras das carapaças para machos e fêmeas das espécies coletadas durante maio/08 a abril/2009 em Balneário Camboriu, SC. *F (OV)= fêmea ovígera.

\begin{tabular}{|c|c|c|c|c|}
\hline \multirow{2}{*}{ Espécies } & \multirow{2}{*}{$\begin{array}{c}\mathrm{N}^{\circ} \text { de } \\
\text { Tombamento }\end{array}$} & \multicolumn{3}{|c|}{ Largura da carapaça $(\mathrm{mm})$} \\
\hline & & MACHOS & FÊMEAS & $F(O V)$ \\
\hline S. carolinensis & FURG-3255 & $16,64-16,69-19,73-22,38$ & & \\
\hline H. arcuata & FURG-3253 & 13,60 & & \\
\hline P. tuberculata & FURG-3254 & $5,83-9,48$ & 5,56 & 7,67 \\
\hline
\end{tabular}

A parte sistemática foi baseada em Melo (1996) $\mathrm{E} \mathrm{Ng}$ et al. (2008).

\section{Diagnose}

Speocarcinus carolinensis Stimpson, 1859 (Figura 1a) Carapaça quase lisa, pontuada, obscuramente granulada junto às margens $e$ pubescente. Região gástrica e subdivisões bem definidas. Margem ânterolateral com 5 dentes, incluindo 0 orbital externo. Segundo dente arredondado e nem sempre distintamente separado do primeiro. Últimos três dentes agudos $e$ 
moderadamente proeminentes. Margens pósterolaterais paralelas. Fronte cerca de $1 / 4$ da largura da carapaça, pouco sinuosa e com reentrância mediana. Pedúnculo ocular com constrição junto à córnea. Quelípodos robustos, quase lisos e com margens pilosas. Mero com forte dente agudo ou espinhoso na face superior. Margem interna do carpo granulada, com espinho obtuso no ângulo interno. Face externa da palma irregular. Dátilo da quela maior com forte dente na base. Pereópodos com margens pilosas (Melo 1996).

Pyromaia tuberculata (Lockington, 1877) (Figura 1b) apresenta carapaça piriforme, com as partes elevadas granuladas e tuberculadas. Um grande tubérculo nas regiões mesogástricas, cardíacas e intestinal. Primeiro somito abdominal com tubérculo curto e espiniforme. Esterno bem granulado e profundamente sulcado entre os esternitos. Quelípodos fortes, com a palma inflada, esparsamente granulada (Melo 1996).

Hypoconcha arcuata Stimpson, 1858 (Figura 1c) apresenta carapaça larga e achatada dorsoventralmente. Esterno e abdome granulados. Margem frontal da carapaça semi-circular, densamente ciliada e com profunda fissura mediana. Olhos antenas e antênulas localizados em depressões profundas. Terceiro par de maxilípodos fechando completamente a cavidade bucal. pereópodos 4 e 5 dobrados sobre a carapaça (Melo 1996).
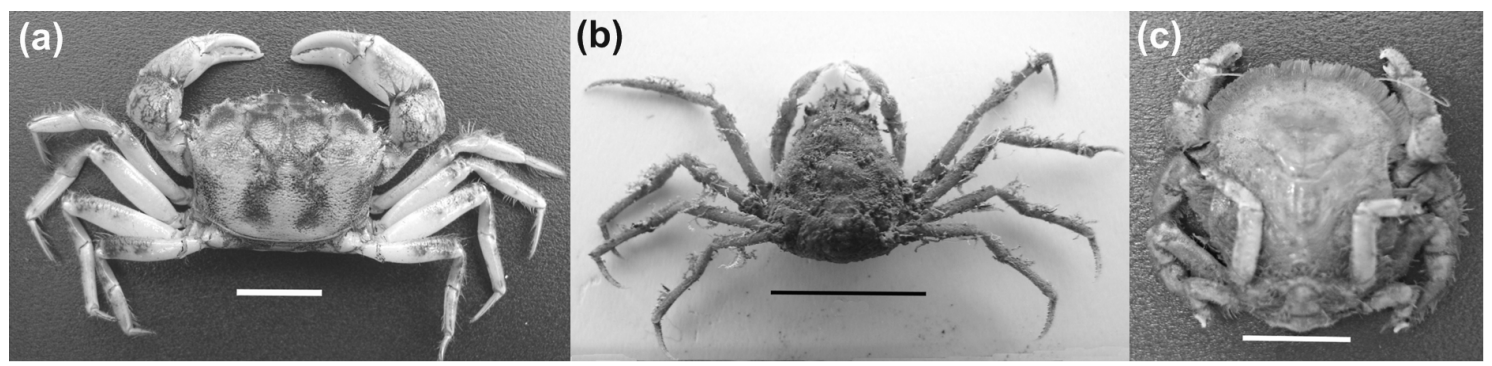

Figura 1. Vista dorsal de (a) Speocarcinus carolinensis, (b) Pyromaia tuberculata e (c) Hypoconcha arcuata. $($ Escala $=1 \mathrm{~cm})$.

\section{LITERATURA CITADA}

MELO, G.A.S. 1996. Manual de identificação dos Brachyura (Caranguejos e Siris) do litoral brasileiro. São Paulo, Ed. Plêiade, 603p.

MELO, G.A.S. 1999. Infraordem Brachyura (siris e caranguejos: espécies marinhas e estuarinas). In: BUCKUP, L.; BONDBUCKUP, G. Os crustáceos do Rio Grande do Sul. Porto Alegre: Ed. Universidade/UFRGS. P. 195-236.

NG, P.K.L, GUINOT, D. \& DAVIE, P.J.F. 2008. Systema Brachyurorum: Part I. An annotated checklist of extant brachyuran crabs of the world. The Raffles Bulletin of Zoology, Singapure, v. 17, p. 1-286. 